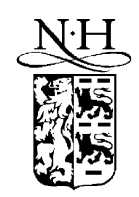

ELSEVIER
Applied Surface Science 180 (2001) 191-199 applied

surface science

www.elsevier.com/locate/apsusc

\title{
Classification of surface structures on fine metallic wires
}

\author{
E. Bernabeu ${ }^{\mathrm{a}}$, L.M. Sanchez-Brea ${ }^{\mathrm{a}}$, P. Siegmann ${ }^{\mathrm{a}}$, J.C. Martinez-Antón ${ }^{\mathrm{a},{ }^{*} \text {, }}$ \\ J.A. Gomez-Pedrero ${ }^{\mathrm{a}}$, G. Wilkening ${ }^{\mathrm{b}}$, L. Koenders ${ }^{\mathrm{b}}$, F. Müller ${ }^{\mathrm{b}}$, \\ M. Hildebrand ${ }^{\mathrm{c}}$, H. Hermann ${ }^{\mathrm{c}}$ \\ ${ }^{\mathrm{a}}$ Facultad de Ciencias Físicas, Departamento de Óptica, Universidad Complutense de Madrid, \\ Ciudad Universitaria s.n., 28040 Madrid, Spain \\ ${ }^{\mathrm{b}}$ Labor 5.12 Mikrotopographie, Physikalisch Technische Bundesanstalt, Bundesallee 100, 38116 Braunschweig, Germany \\ ${ }^{\mathrm{c} I n s t i t u t e}$ für Metallformung, TU Bergakademie Freiberg, Bernhard-von-Cotta-Strasse 4, D-09596 Freiberg, Germany
}

Received 23 March 2001; accepted 12 April 2001

\begin{abstract}
In this report a classification of the main surface structures found on fine metallic wires is carried out (between $\sim 20$ and $500 \mu \mathrm{m}$ in diameter). For this, we have analyzed a series of wires of different metallic materials, diameters and production environments by scanning electron microscopy, atomic force microscopy, and confocal microscopy. A description and the images of the structures is given and, in addition, a nomenclature to be used by manufacturers, customers and researches is proposed. With this information the surface quality of fine metallic wires may be improved in a fabrication level. One of the objectives of this catalogue of defects is to serve as a basis for measuring the quality of the surface of the wires during the production process and the development of a measuring device for that purpose. (C) 2001 Elsevier Science B.V. All rights reserved.
\end{abstract}

PACS: 68.37.-d; 68.37.Hk; 68.37.Ps; 81.20.Hy

Keywords: Wires; Surface structure; Roughness; Surface defects; Tribology; Metallic surfaces

\section{Introduction}

Increased scientific knowledge and the experience gained in practical work are decisive for the selection of the correct technology that will produce wires of high dimensional accuracy and superior surface finishing. It is well known that current methods for determination of the surface quality of fine wires are not sufficient where demanding applications are involved. The surface quality required depends on the applica-

\footnotetext{
* Corresponding author. Tel.: +34-91-394-4629; fax: +34-91-394-4683.

E-mail address: fiopt12@emducms1.sis.ucm.es

(J.C. Martinez-Antón).
}

tion and the final user, and therefore novel methods are required which pay due regard to the customers needs.

The surface quality and the geometrical and dimensional accuracy of fine wires are decisively influenced by the stress, deformation and temperature conditions, as well as the kinetic and tribological conditions occurring at the die/wire interface. In this regard friction plays a critical role in the deformation process. The functional effect of friction consists in improving the fineness of the surface structure.

A lasting and effective improvement of the surface quality is only achieved when an intimate contact between die and wire leads to significant changes in the structure and form of the surface region of the wire. The technological requirements to achieve this goal 
are a condition of mixed friction in the lubrication process, high contact stresses and inhomogeneous deformation concentrated in the surface region of the wire. The ability of the lubricant to withstand the high and variable pressures in the contact area is decisive in any surface quality improvement in fine wires. Also, the surface quality of the pre-material determines more or less the surface quality of the final product. Wire drawing is characterized by a continual generation of new surface, which can be up to a ratio of 2.8 the final surface to the original surface, given by recent technology. As more and more new surface is generated the lubricant film becomes thinner. If the lubricant film is reduced below the boundary lubrication limit then surface damage is unavoidable.

The temperature increase that takes place during wire drawing adversely affects the tribological processes and thus can lead to a reduced surface quality for ultra-fine wires. It is therefore important that the lubricant used must completely wet the area between die and wire and during the generation of new surface it must guarantee the separation of wire and die. The lubricant film must remain stable and must not rupture. The newly formed surface is very physicochemically reactive and pressure welds easily occur [1-3].

These are the fundamental relationships that determine the achievement of the desired surface quality in ultra-fine wires. Defective pre-material or disruptions in the sensitive tribological/cold work system are the

Table 1

Surface structures and categories in which they are divided

\begin{tabular}{ll}
\hline Category & Structure \\
\hline Laps & Surface scrap \\
& Spills \\
& Flakes \\
Local structures & Holes \\
& Inclusions \\
& Pores \\
Continuous structures & Protuberances \\
& Die lines \\
& Drawing groves \\
Shape deviations & Ridges \\
& Chatter marks \\
Damages & Flattened areas \\
& Scratches \\
\hline
\end{tabular}

reasons for obtaining unsatisfactory surface quality in ultra-fine wires.

As very little information is available on surface defects in wires from 20 to $500 \mu \mathrm{m}$ diameter, this work

(a)

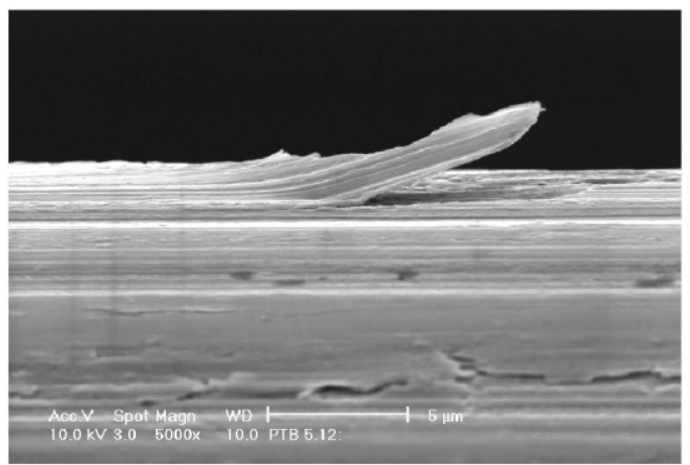

(b)

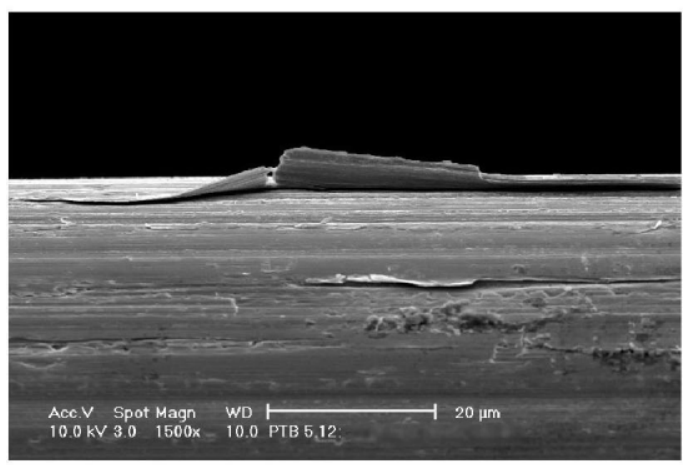

(c)

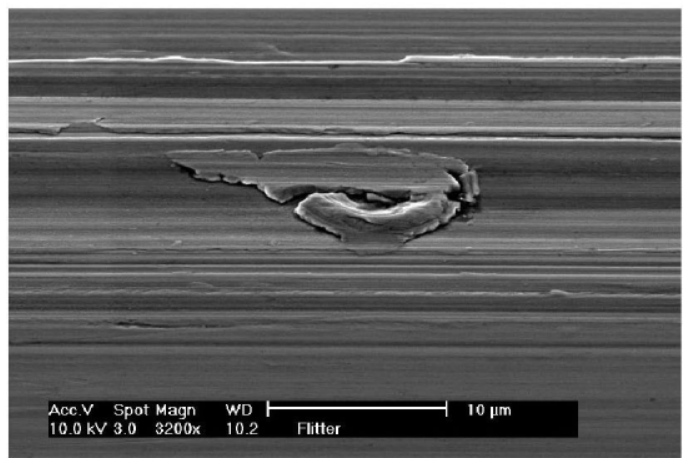

Fig. 1. SEM images of laps. (a) Surface scrap, (b) spill, and (c) flake. The material is Inconel 601 for (a) and (b) and metal coated steel wire, carbon content about $0.8 \%$ for (c). 
has collected and documented these defects. We present a compilation of the surface structures found over the surface of metallic wires in the mentioned range of diameters, which may serve as a guide to help manufacturers and users for wire quality assessment. Images of the various surface structures are given.

We have classified the surface structures into categories, according to their shape. A probable origin for each structure is also given, which may be useful to wire producers.

An additional problem is the lack of a common nomenclature among the manufacturers, users and researchers, which gives rise to misunderstandings. For this reason we have explicitly proposed a definition of the surface structures found, showing a typical image of each structure and giving them a name.

(a)

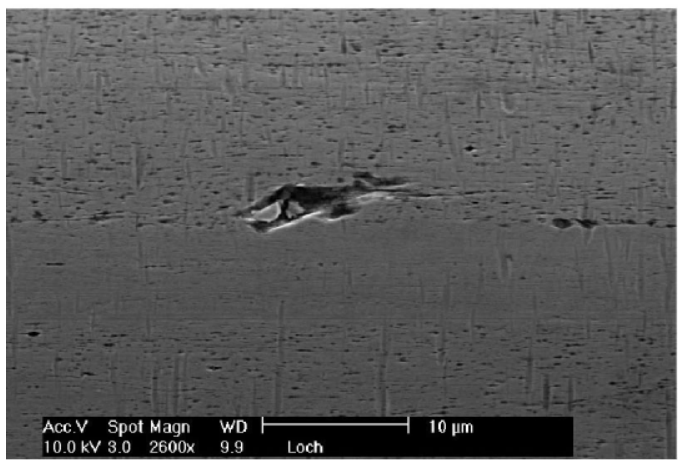

(c)

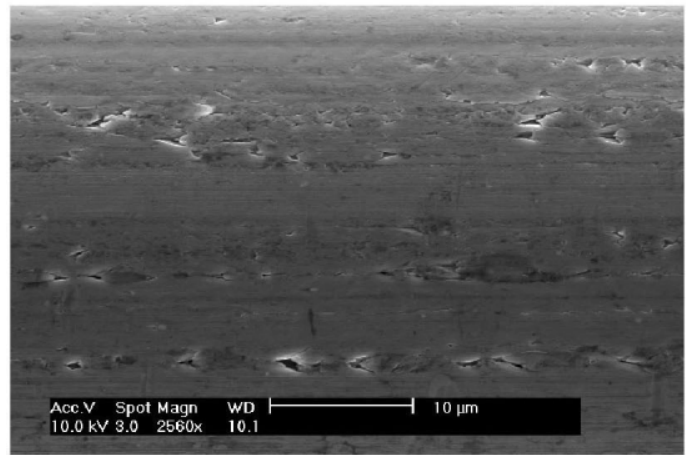

2. Measurement of surface structures on metallic wires

The technique that we have mainly used for surface characterization of metallic wires has been scanning electron microscopy (SEM), since it has the best resolution and depth of field. It presents a wide explored surface range in comparison to the wire diameters considered $(<600 \mu \mathrm{m})$.

SEM, however, also presents several disadvantages: it is not possible to obtain topographical measurements for the determination of depths and the dispersed electrons are influenced, not only by the slope, but also by its curvature and, as a consequence, the edges are enhanced.

For all these reasons, to complement SEM, when the determination of the size of the structure is necessary, we have used the atomic force microscopy

(b)

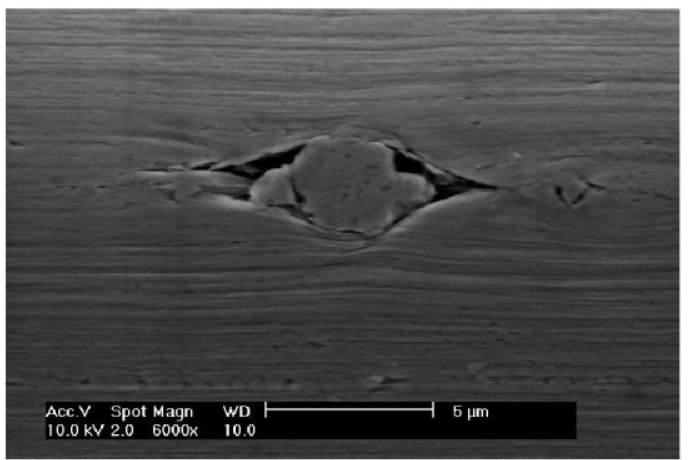

(d)

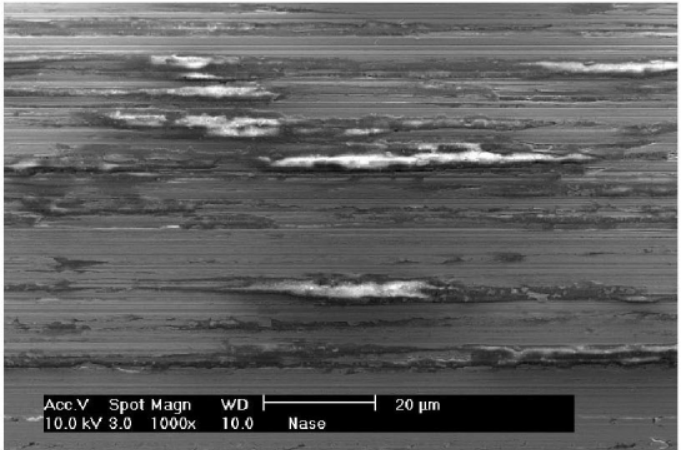

Fig. 2. SEM images of local structures: (a) hole, (b) inclusion, (c) pores, and (d) protuberances. The material of the wires is (a) high grade steel wire, (b) AISI 304L, (c) AlMg 5 and (d) steel wire, carbon content about $0.6 \%$. 
(AFM) [4]. AFM is a suitable technique for the characterization of plane [5] and cylindrical surfaces $[6,7]$. The main problem for AFM is the surface range, which is around $100 \times 100 \mu \mathrm{m}^{2}$ in the $X Y$ axis and $10 \mu \mathrm{m}$ in the vertical axis. Nevertheless, modern AFM systems present much larger ranges $(\sim \mathrm{mm})$ which permit its use for fine wires.

Confocal microscopy is another method to complement SEM. The idea behind it is to obtain a series of images of one surface, each one taken with a successively altered focus. For each image the part of the surface in the respective focal plane is displayed sharply, while all other points of this surface outside the focal plain are blurred. Thus, a height information is received for every point of the surface. Although it is

(a)

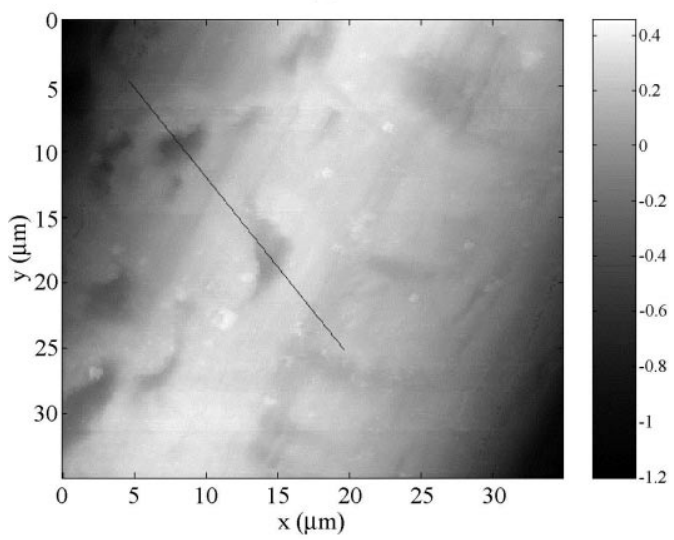

(c)

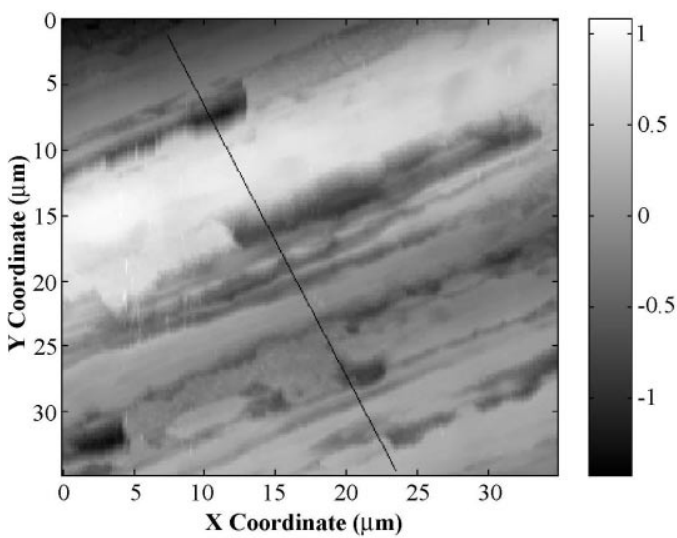

based on optical microscopy and it is limited in resolution and magnification, confocal microscopy is a convenient method to obtain three-dimensional topologies of any solid probe material, without the need to process the surface in a special way or to work in a vacuum environment.

\section{Classification of structures}

We have obtained more than 500 images by SEM and around 150 measurements by AFM, on about 40 samples of fine wires of various diameters and materials (see the figure captions for a description of the wires). In most of the images we have appreciated (b)

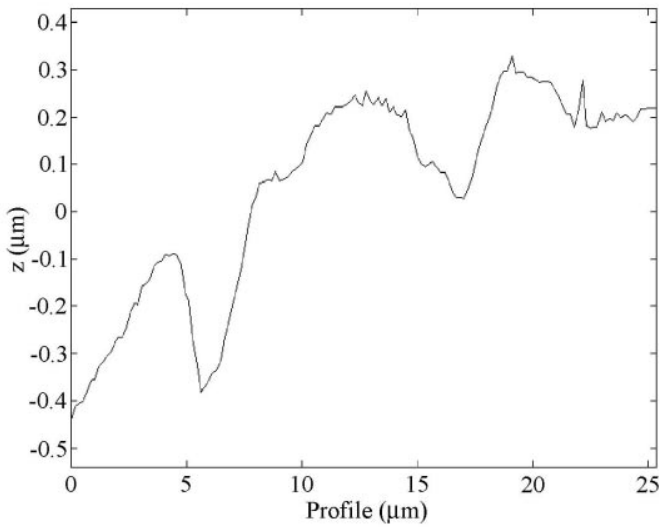

(d)

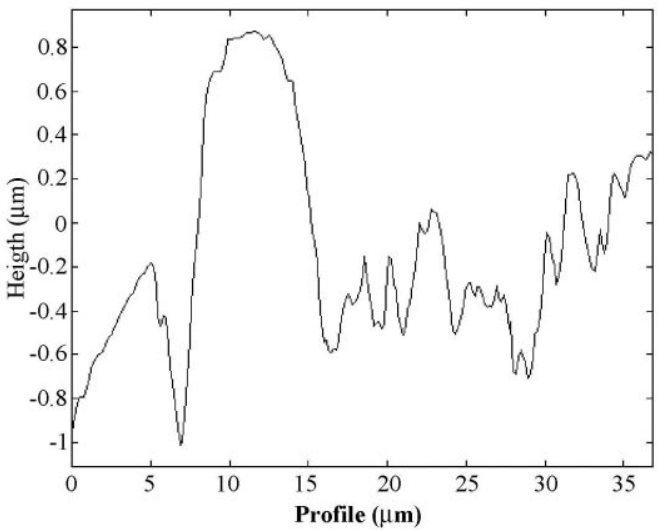

Fig. 3. AFM images and profiles for (a), (b) pores, and (c), (d) protuberances. 
differences in the form of the wire compared to the cylindrical shape. In Table 1 the structures found are shown, classified into five main categories. Each category presents several structures with a similar aspect, but with different possible origins.

\subsection{Laps}

1. A surface scrap is a loosening of surface material only partly connected to the wire surface (Fig. 1a). Detachment appears along the wire axis. A possible origin of this structure is a lateral defect prior to drawing process, defect which is drawn over in the following working steps, leading to material detaching from the surface.

2. Spills are loosening of surface material only partly connected to the wire surface (Fig. 1b). Detachment appears perpendicular to the wire axis. They may be generated by a wire rod defect during hot transformation, overrolling of material; another possibility is a laid down drawing nose in subsequent drawing process.

3. Flakes are drawing scratches with quasi-periodic forcing of abraded material into the scratch (Fig. 1c). Possible origins for this structure are insufficient properties of the drawing process (die-surface, lubricants, etc.) causing an abrasion on the wire surface, which subsequently is pressed into the base material. Their occurrence is increased at soft, uncoated wire materials like aluminum or copper.

\subsection{Local structures}

1. Holes are isolated deepenings into the wire surface, probably caused by rolled-in or drawnin material, originating, e.g. from scales breaking loose or from extraneous material being pressed into the wire surface (Fig. 2a).

2. An inclusion is a material pressed into the wire surface. Its origin is the drawn-in or pressed-in material, originating, e.g. from tool fragments during processing, from incorporation of material into the wire rod surface or from metallurgical incorporation close below the wire rod surface, which appear on the surface during subsequent steps of processing (Fig. 2b).
3. Pores are multiply occurring small deepenings in the wire surface due to improper pre-processing of the wire rod. Pores may appear due to overetching

(a)

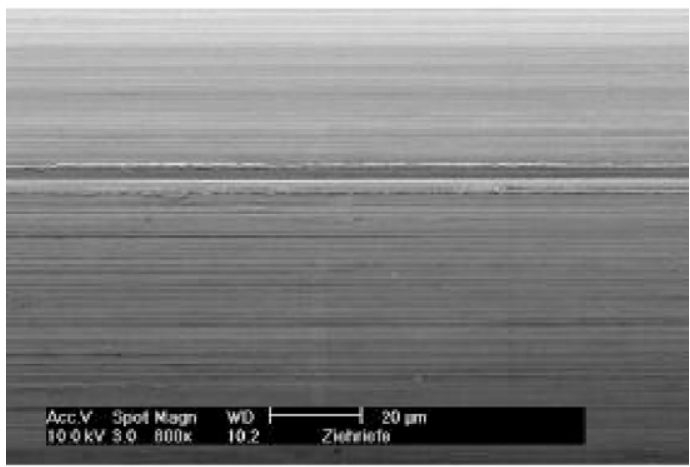

(b)

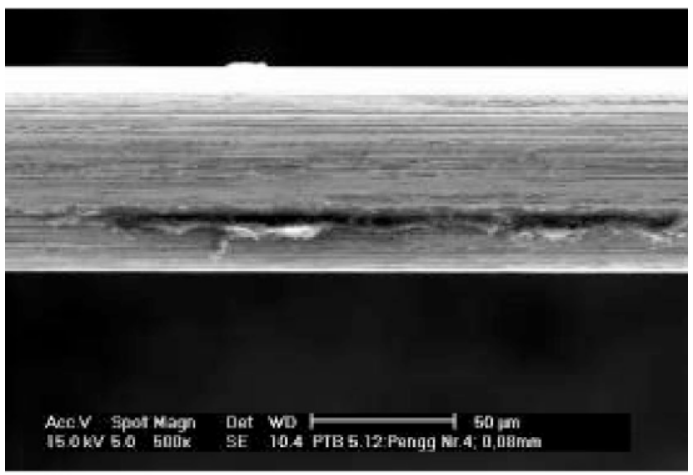

(c)

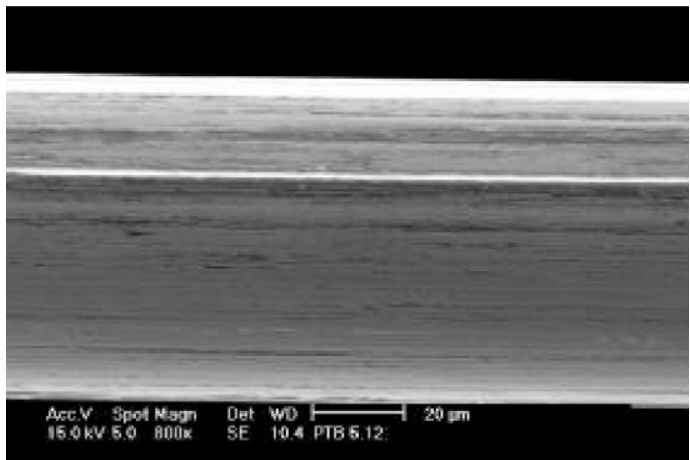

Fig. 4. SEM images of continuous structures. (a) Die lines, (b) drawing grooves, (c) ridges. The material of the wires is, in the three cases, carbon steel, carbon content about $0.75 \%$. 
or corrosion of the original material, if it is not resistant to corrosion (Fig. 2c, SEM; Fig. 3a and b, AFM).

4. Protuberances are linear protrusions of limited length on the wire surface parallel to its axis (Fig. 2d, SEM; Fig. 3c and d, AFM). A possible origin for this structure is that the die inner surface is too rough or that a coating of initial material (lubricant carrier) is insufficient or too inhomogeneously distributed on the surface. The occurrence of this surface structure is always combined with increased die wear.

(a)

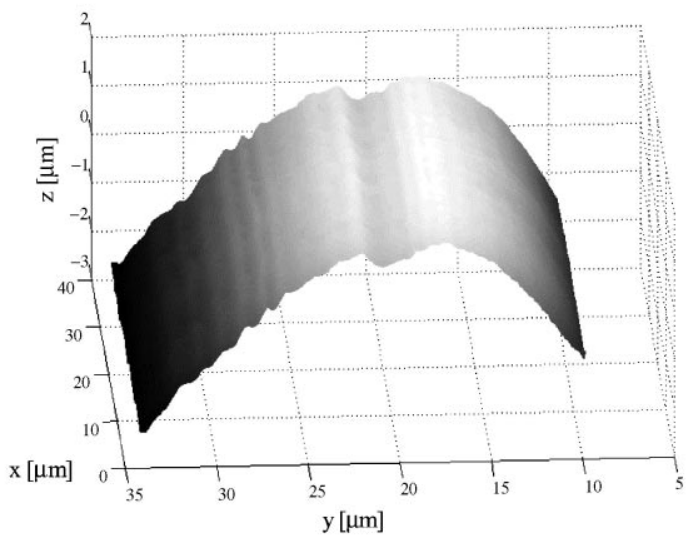

(c)

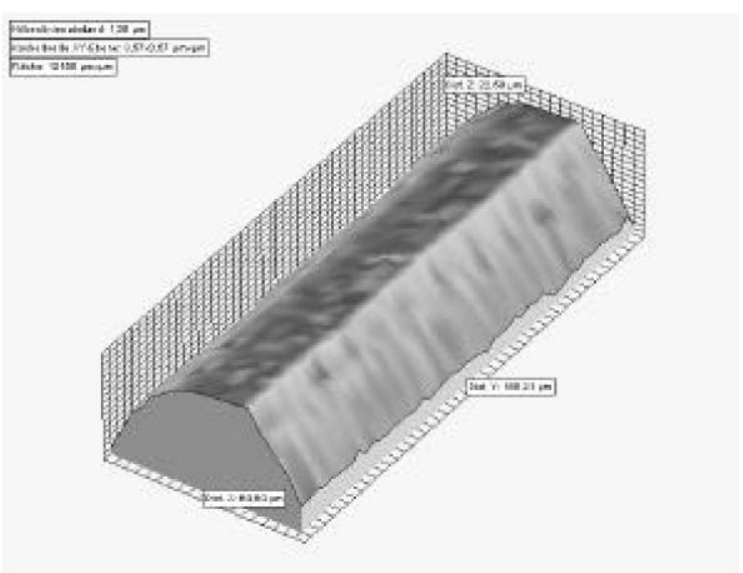

\subsection{Continuous structures}

1. Die lines are linear uniform grooves parallel to the wire axis without obvious limitation of its length caused by insufficient lubrication during drawing, deficient quality of die-surface (Fig. 4a, SEM; Fig. $5 \mathrm{a}$ and $\mathrm{b}, \mathrm{AFM}$ ).

2. Drawing grooves are linear, broad deepening with limited length, parallel to the wire axis (Fig. 4b). As a rule, such deepenings do have more or less frayed-out rims. They may be caused by foreign particles in the reduction area of the die.

(b)

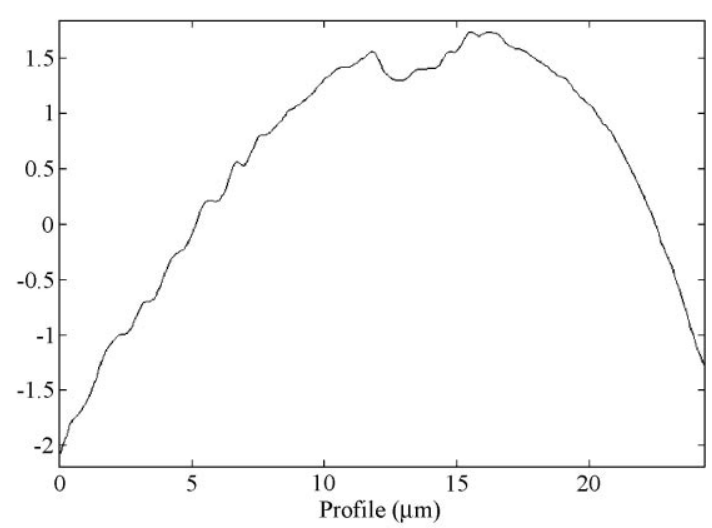

(d)

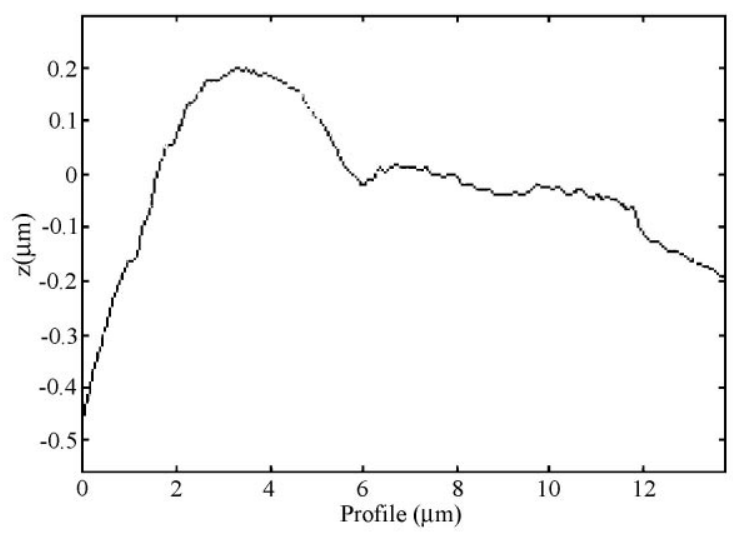

Fig. 5. (a) Three-dimensional image of a die line obtained by AFM and (b) linear profile. In (c) we can see a three-dimensional image of a ridge obtained by confocal microscopy and in (d) its profile obtained by AFM. 
(a)

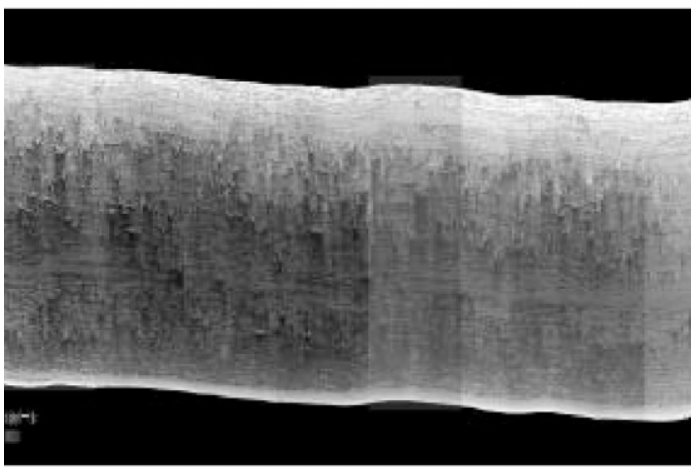

(b)

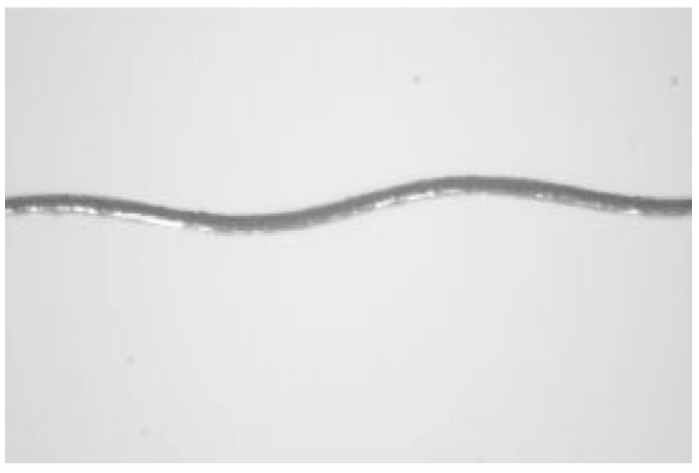

(c)
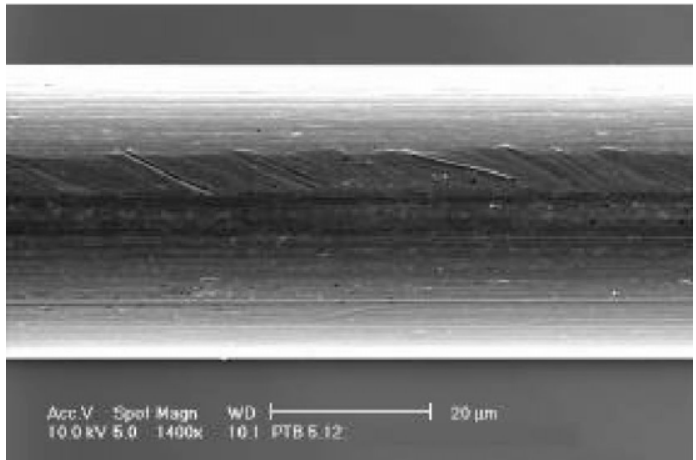

Fig. 6. SEM images of shape deviations. (a) Chatter marks in a carbon steel wire (carbon content about $0.7 \%$ ). As the length of the chatter marks is larger than the length of the SEM range, this image has been obtained overlapping several SEM images. (b) is a photograph, obtained with an optical microscope of a brass wire with waviness. In (c) we can see flattened areas in an AISI 304 wire.
3. A ridge is a linear uniform protrusion parallel to the wire axis without obvious limitation of its length (Fig. 4c, SEM; Fig. 5c, confocal microscopy; Fig. 5d, AFM). Its origin is due to a damaged die, e.g. hairline crack on the die-surface or fracture in the reduction area of the die.

\subsection{Shape deviations}

1. Chatter marks are deviations of the wire axis from a linear course and variation of the wire diameter,

(a)

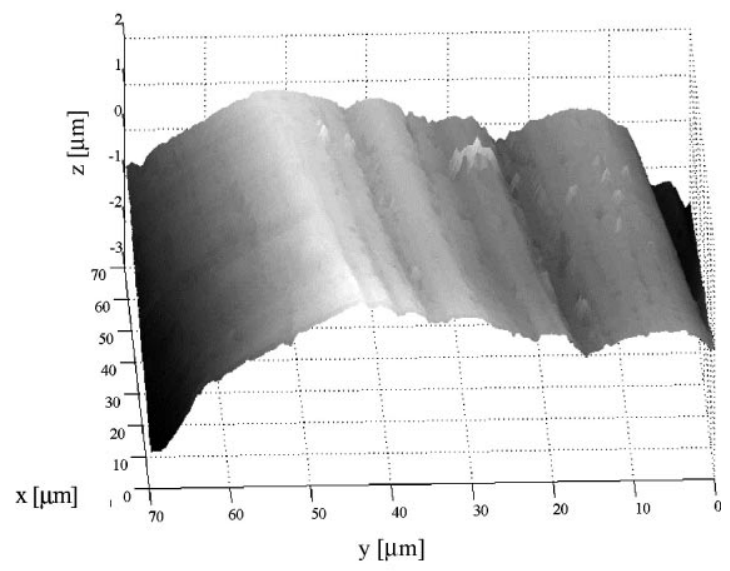

(b)

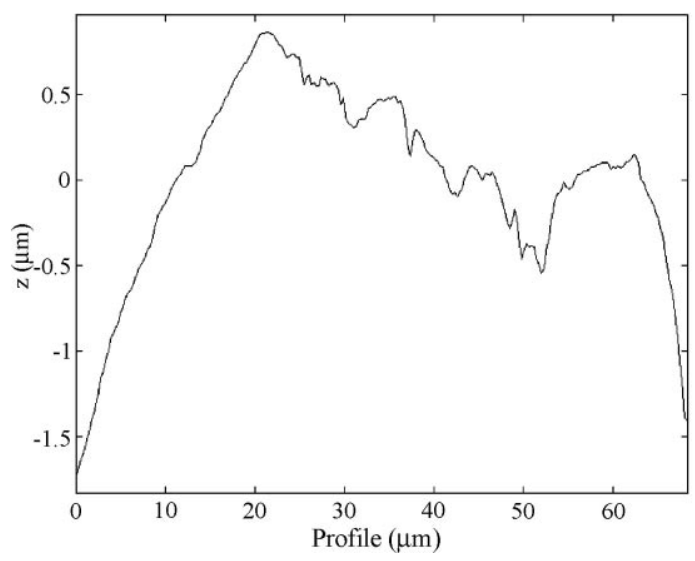

Fig. 7. (a) Three-dimensional image of a flattened area obtained by AFM and (b) linear profile. 
(a)

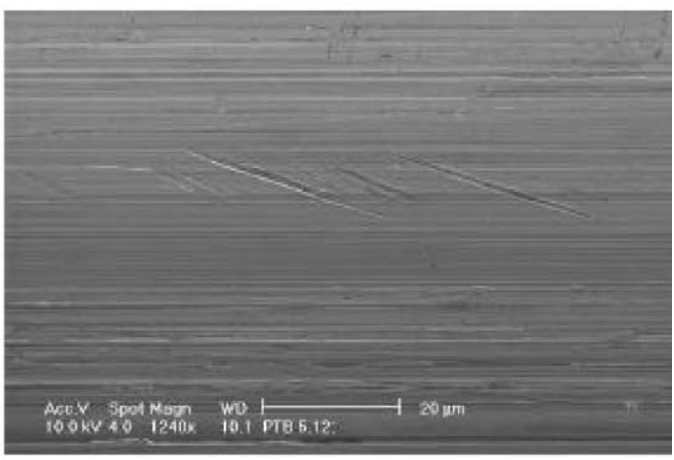

(b)

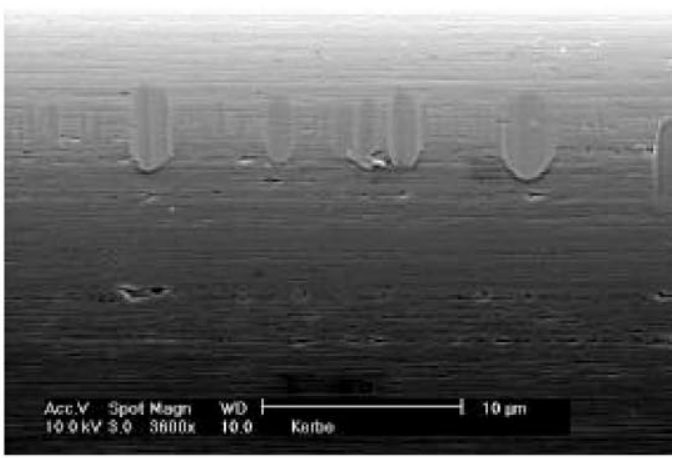

(c)

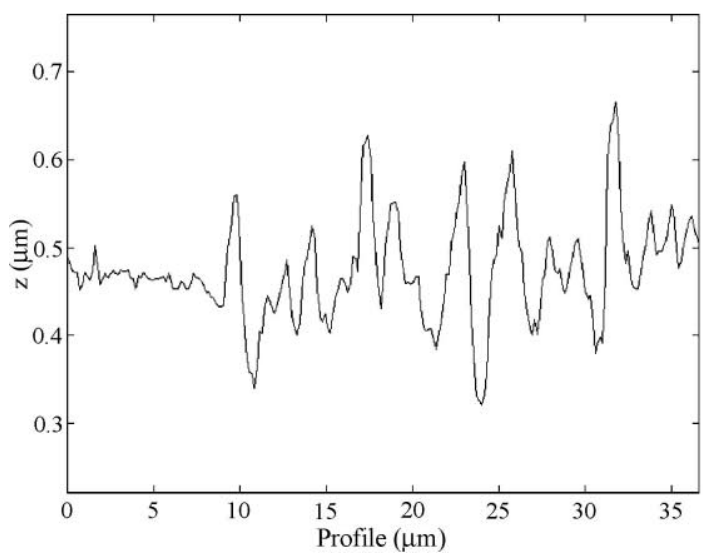

Fig. 8. SEM images of damages. (a) Scratches in a carbon steel wire and (b) notches in an AISI 304 wire. In (c) a profile of the notches obtained by AFM. leading to a wavy surface (Fig. 6a). The origin of this structure are wire vibrations caused by (a) die adjustment and mounting, (b) irregularities of the drawing capstan, (c) wrong die set, too much slip, (d) insufficient wire lubrication.

2. Waviness is a periodic deviation of the wire axis from linearity whose origin is a defective or unsuitable straightening device (diameter of rolls, distance between rolls, number of rolls) and also a wrong roll arrangement (Fig. 6b).

3. Flattened areas are areas parallel to the wire axis without obvious limitation in length, where the wire surface is leveled, thus not following the curvature given by the wire diameter (Fig. 6c, SEM; Fig. 7a and b, AFM). This shape deviation is caused by defective wire guidance.

\subsection{Damages}

1. Scratches are linear deepenings of limited length, being deeper than its width originated by wire brushing against the flank of a guide pulley (scraping damage) (Fig. 8a).

2. Notches are linear deepening of limited length, being broader than deep (Fig. 8b, SEM; Fig. 8c AFM). They may be due to drawing capstan or guide pulley with damaged working surface causing indentations.

\section{Conclusion}

In this work we have inspected a number of metallic wires with different materials, diameters and production environments by SEM, AFM and confocal microscopy. We have analyzed the surface structures found, indicating their possible origin, and showing typical images of these structures. We have also proposed a nomenclature for each structure.

\section{Acknowledgements}

This work has been supported by European Union within the frame of the EU Research Program "Standards Measurement and Testing", project SMT4CT97-2184 "DEFCYL: Detection of DEFects in CYLindrical surfaces". 


\section{References}

[1] W.G. Drossel, M. Hildebrand, O. Pawelski, FEM-analysis of the friction process in section drawing, Steel Res. 69 (8) (1998) 330-333.

[2] M. Hildebrand, Die bedeutung der schmierstoffe für die vorgänge in der wirkfuge und der beanspruchung der werkzeuge beim ziehen, EuroWire 2 (3) (1999) D12-D16.

[3] M. Hildebrand, H. Hermann, Die wechselwirkungen von lokaler schmierfilmausbildung und örtlicher oberflächenfeingestalt bei der kaltumformung, DFG-Abschlußbericht, Institut für Metallformung der TU Bergakademie Freiberg, November 2000.
[4] G. Binnig, C.F. Quate, Ch. Gerber, Atomic force microscope, Phys. Rev. Lett. 56 (9) (1986) 930-933.

[5] S. Gomez, K. Hale, J. Burrows, B. Griffiths, Measurements of surface defects on optical components, Meas. Sci. Technol. 9 (1998) 607-616.

[6] L.M. Sanchez-Brea, J.A. Gomez-Pedrero, E. Bernabeu, Measurement of surface defects on thin steel wires by atomic force microscopy, Appl. Surf. Sci. 150 (1-4) (1999) 125-130.

[7] L.M. Sanchez-Brea, J.A. Gomez-Pedrero, E. Bernabeu, Analysis and characterization of surface defects on thin steel wires by atomic force microscopy, in: Proceedings of the Wire and Cable Technical Symposium at Interwire '99, Wire Association International, Atlanta, 1999, pp. 189-192. 